\title{
The Use of Zirconium in the Management of Replacing Single Missing Tooth: A Clinical Report
}

\author{
N Hassine ${ }^{1}$, R Hadhri ${ }^{1}$, S Nasri ${ }^{1}$, B Harzallah ${ }^{2}$, M Cherif ${ }^{3}$ and D Hadyaoui ${ }^{2 *}$ \\ ${ }^{1}$ Department of Fixed Prosthodontics, Faculty of Dental Medicine, Tunisia \\ ${ }^{2}$ Professor, Department of Fixed Prosthodontics, Tunisia \\ ${ }^{3}$ Professor and Head, Department of Fixed Prosthodontics, Tunisia
}

Submission: November 06, 2017; Published: May 30, 2018

*Corresponding author: Dalenda Hadyaoui, Professor, Department of Fixed Prosthodontics, Faculty of Dental Medicine, Monastir, Tunisia, Email: dalendaresearch@gmail.com

\begin{abstract}
The best treatment option to replace a single missing tooth is usually based on the provision of dental implant. In some cases dental implant cannot be used, for that reason the second treatment option is fixed partial denture. Metal ceramic restorations have been used in fixed prosthodontics for long time, but many disadvantages limits its uses such us the potential metal allergy and the lack of esthetics. On the other hand, the use of all-ceramic materials has known a great increase thanks to the introduction of zirconia to fixed prosthodontics over a decade ago. Zirconia frameworks are manufactured using computer-aided design/computer-assisted manufacturing (CAD/CAM). This high strength material establishes high qualities from the functional, esthetic, and biological points of view. This article describes the use of zirconia for the fabrication of a fixed partial denture restoring both esthetics and function.
\end{abstract}

Keywords: Zirconia; Implant; Fixed Partial Denture; Esthetic; Metal-Free; CAD/CAM.

\section{Background}

Today it's possible to replace a missing tooth using different treatment modalities. During the past decade, dental implants have been the best choice, especially in cases when the abutment teeth are sound [1]. Nevertheless, implant therapy can sometimes be compromised by anatomical conditions. In fact, implant placement in the posterior maxilla region is often challenging due to alveolar bone resorption and sinus pneumatization phenomenon that are fastened with tooth extraction. To surmount these difficulties, sinus bone grafting and maxillary sinus lifting are frequently indicated [2]. In our case, the Cone BeamComputed Tomography (CBCT) showed that the alveolar crest is insufficient for implant placement. Also, researches have proved a positive correlation between pre-operative sinus disease and the occurrence of acute post-operative sinusitis in case of maxillary sinus grafting [3]. Consequently, an implant placement cannot be indicated and fixed partial denture seems to be a suitable solution for our case. For fixed dental prostheses the treatment outcome depends on a variety of designs and restorative materials which are available [4]. In recent years, there have been promising results when zirconia frameworks were used as an alternative to metal based fixed partial dentures (FDPs) [5]. Since its introduction in 1960, zirconia attracted the attention of dental researchers with its promising in vitro properties [6]. The qualities that make it a reliable restorative material are superior resistance to fracture compared to other conventional dental ceramics, biocompatibility, enhanced esthetics and its marginal fit which meets the clinical requirement [7].

The following case report describes the replacement of the first missing premolar with porcelain fused to CAD/CAM-fabricated zirconia frameworks to design a patient-specific prosthesis.

\section{Case Report}

The case we present here is about a 30 years old female patient with unremarkable medical history, who presented to the Fixed Prosthetics Department of the Dentistry Clinic, University of Monastir. Her chief complaint was to replace the first right maxillary premolar for esthetic and functional reasons (Figure 1).

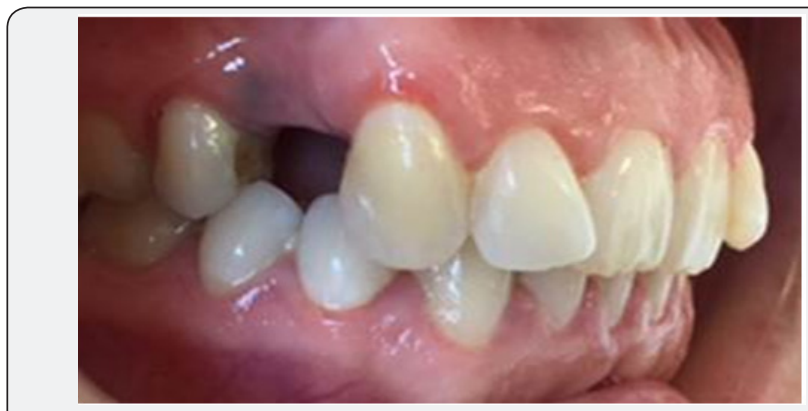

Figure 1: Pre-operative lateral view showing the missing of upper first premolar 


\section{Advances in Dentistry \& Oral Health}

Concerning her medical history, her only complain was a chronic sinusitis. Intraoral examination showed that the abutment teeth were with healthy periodontium and the attached gingiva was adequate. Resin filling was found on the distal surface of the upper right canine and the mesial surface of the second right premolar.

For prosthetic treatment, two methods were chosen: implant supported single crown, and zirconia FPD. Implant replacement was excluded from the list because the measure of the length of the crest showed that the alveolar crest is insufficient for implant placement. Moreover, the chronic sinusitis counters the indication for maxillary sinus floor elevation. Thus, the use of zirconia FPD was suggested and accepted by the patient. Upon her agreement, abutment preparation was undertaken. . The design of the tooth preparation should encompass necessary reduction relative to tooth position and the requirements of the restorative material. The abutment teeth $(\# 13, \# 14)$ for zirconium restorations were prepared. The finish line was a uniform deep chamfer (or could be a marginal shoulder) of depth 0.8 to $1 \mathrm{~mm}$, allowing a slight subgingival marginal location of approximately $0.5 \mathrm{~mm}$. Internal angles should be rounded [8] (Figure 2).

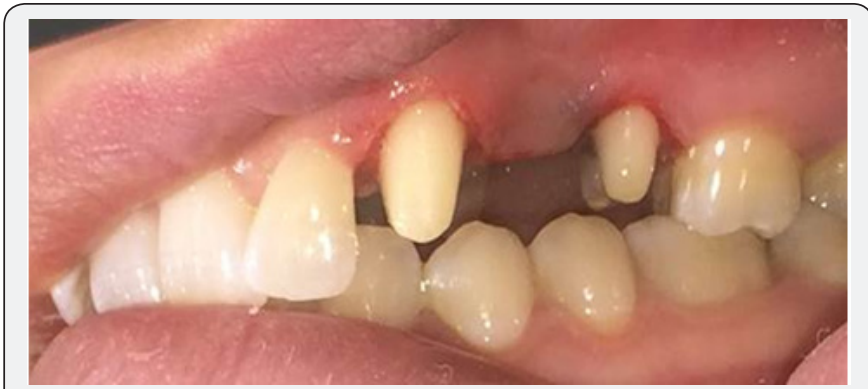

Figure 2: Teeth preparation.

After the retraction cord was inserted, a simultaneous double mixed impression was taken using a silicon impression material (light and heavy silicon) (Figure 3). A temporary restoration was made directly on the prepared teeth with composite resin. The master cast was obtained. Models were scanned with an optic scanner and the framework was designed and milled by CAD/CAM (Figure 4).

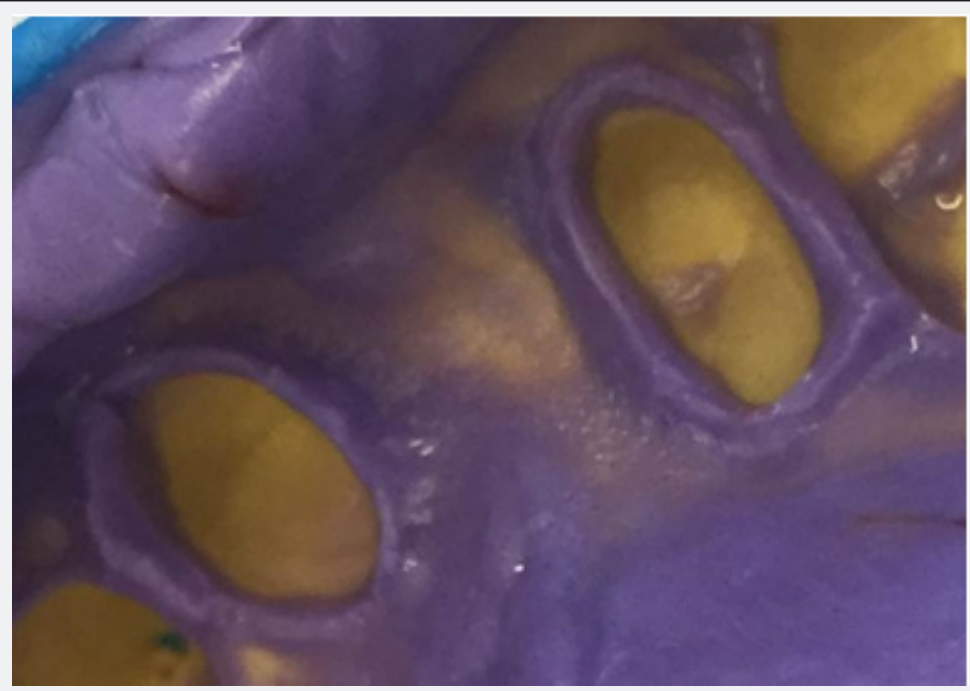

Figure 3: The impression of the prepared teeth including key areas such as the margins of preparations.
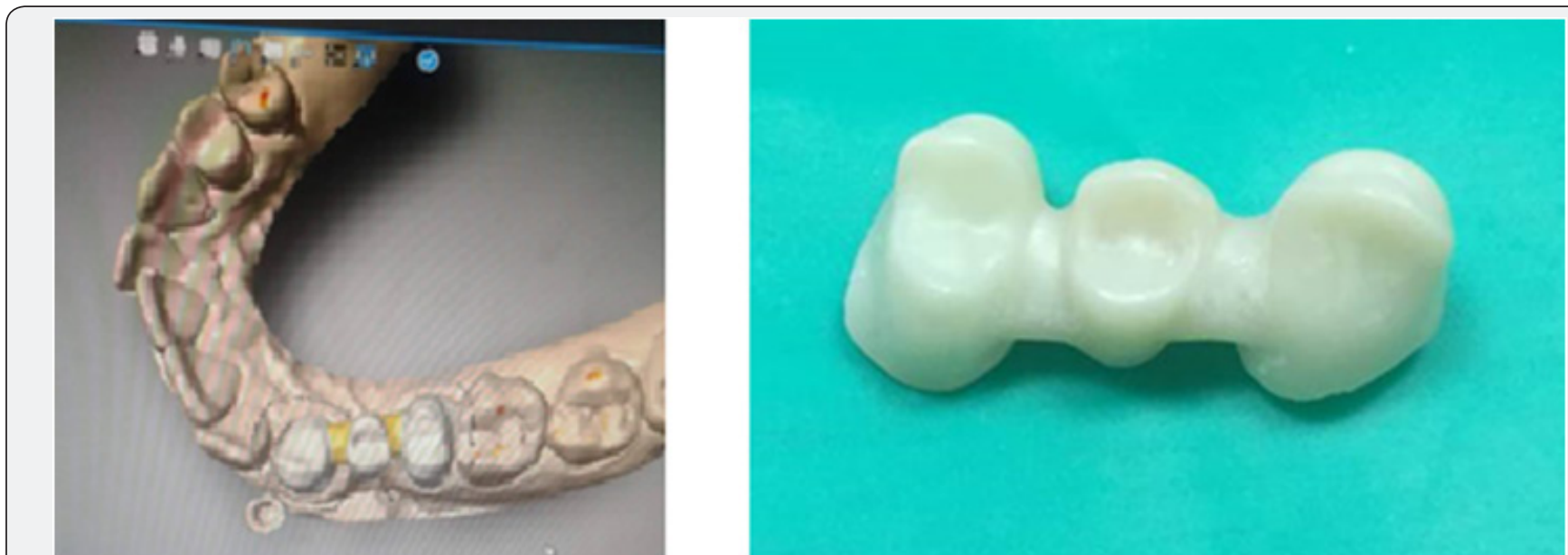

Figure 4: The zirconia framework. 

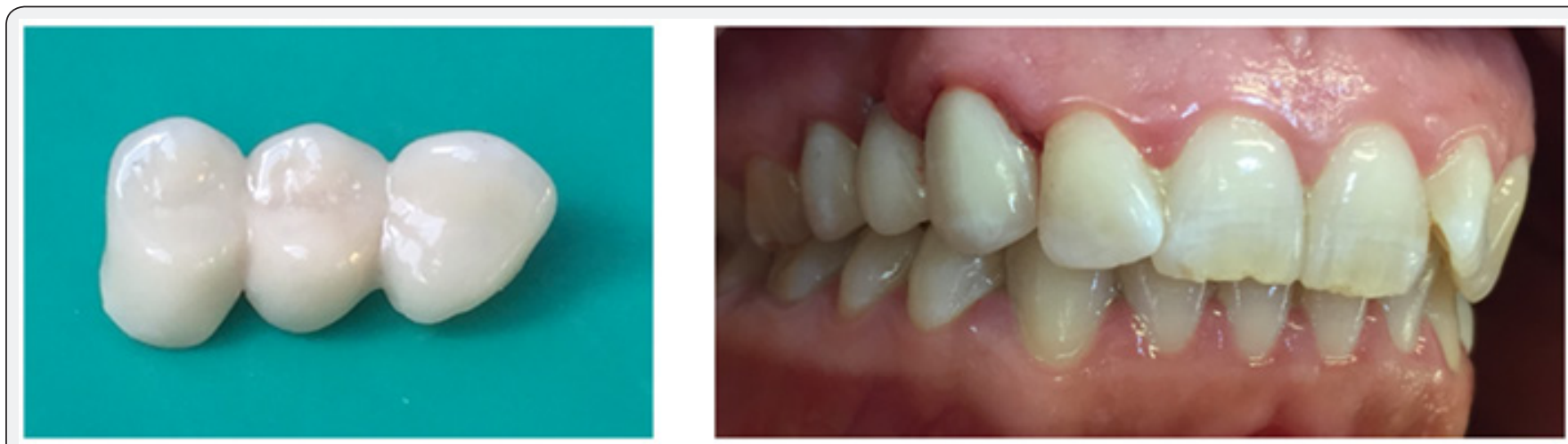

Figure 5: Final restoration.

At the initial trial insertion, different points were checked including adequate seating of the prosthesis, marginal fit, and pontic shape. Then, the shade was defined and recorded. The framework was coated manually with a covering feldspathic ceramic. The occlusion (static and dynamic occlusion, the canine guidance) and esthetics were checked intra-orally. After ceramic glazing, the prosthesis was cemented with glass ionmer cement. Oral hygiene instruction and regular check-up were administered. In the recall check-ups, no complications were observed, and the patient was satisfied with her prosthesis (Figure 5).

\section{Discussion}

Loss of teeth can have esthetic, functional, psychological, and social impacts on the life of individuals. This explains the necessity for prosthetic rehabilitation to enhance quality of life [9]. Implant supported single crown restoration is often the most preferable treatment modality to replace an extracted upper premolar due to its non-invasive approach, aesthetic outcome, function restoration, stability and high survival rate $[10,11]$.

However, a Single-tooth implant in the posterior maxilla is complicated by reduced bone volume. Moreover, sinus floor elevation is frequently needed to overcome the lack of sufficient jaw bone dimensions. But the chronic sinusitis of our patient counters this procedure. Thus, the clinical disability to create sufficient bone to house the implant has called for an alternative conventional treatment which is Fixed Dental Prosthesis (FDPs).

Traditionally, metal based restorations for fixed dental prostheses were considered as the gold standard for years in prosthetic dentistry especially, that their long term follow up studies have proven their good mechanical properties, their high survival rates and their clinically acceptable quality of their marginal adaptation $[12,13]$. However, the first disadvantage of these prostheses is the luck of esthetics due to the metal substrate which has to be masked with the opaque porcelain [14]. In addition, metal-based prostheses may possibly cause negative reactions [9]. The high aesthetic requirement of the patient ultimately aimed at using free metal fixed partial dentures certainly that the aesthetic result of metal-ceramic restorations are significantly limited due to the absence of translucency caused by the underlying metal grayish shade and the gum coloration due to the metal corrosion phenomenon [12].

Furthermore, all ceramic FDPs as part of restorative materials fulfill perfectly the need for aesthetic and mimic perfectly the natural teeth. But, in the other hand, all ceramic frameworks have low mechanical stability which limited their indication. And, as a compromise between an excellent aesthetic rendering and mechanical strength and toughness, high strength yttrium-oxide partially stabilized zirconia (Y-PSZ) has been used as a framework for bilayered 3 unit FDPs [15].

Zirconium-dioxide exhibited a flexural strength of 900-1200 $\mathrm{MPa}$ and fracture toughness rated from 5 to $10 \mathrm{MP} \mathrm{am}^{1 / 2}$. Its mechanical strength is up to three-times better than conventional all ceramics [16]. Compared to other ceramics, zirconia framework offers another gain such as the reduction in the layer thickness which provides for the veneer ceramic the sufficient space to achieve the desired color [14].

Moreover, the explanation for such better qualities of this 'ceramic steel' [17] result in the way zirconia framework behaves under applied stress. In fact, in the area of a propagating crack, the stress induces a phase transformation. This transformation causes constriction of crack and hardening of the material [18]. The mechanical properties of the zirconia framework have been optimized by respecting their clinical recommendations. Indeed, studies have proved that predominantly short span FDPs have more survival rate comparing to long span FDPs which are related most frequently to technical problems [19]. Also, in order to avoid fracture risk, usually located in the area between the retainer and pontic, the connector dimension was adjusted of $9 \mathrm{~mm}^{2}$ which is recommended for 3 units FDPs [20].

Despite the high fracture resistance of zirconia frameworks, chipping of the veneered porcelain has been noted as a problem in zirconia-based all-ceramic restorations [21]. To solve the chipping problem, it was suggested that monolithic translucent TZP offered higher fracture strength than bilayer veneered zirconia [22]. However, the prevalence of major and minor chipping is difficult to exactly confirm [18]. In addition, the survival percentage of zirconia based prostheses is very good, since the majorities of the veneer fractures are minor ones and do not weaken the esthetic and functional outcomes of the restoration [18]. 
Add to that, from aesthetic point of view, zirconia has a white opaque color which needs masking by veneering it with a more translucent and aesthetic porcelain to enhance a satisfactory aesthetic outcome for the demanding patient [15].

\section{Conclusion}

To meet the demand of today's patients, dental prostheses must take in consideration many properties, including biocompatibility, esthetics, abrasion resistance, color stability and high-strength. Regarding his clinical outcome zirconia was chosen as framework material for all- ceramic FPD for this patient. Many developments were undertaken since the introduction of zirconia, but others improvements are wished to make it become the gold standard in dental prostheses.

\section{References}

1. Misch CE, Misch Dietsh F, Silc J, Barboza E, Cianciola LJ, et al. (2008) Posterior implant single-tooth replacement and status of adjacent teeth during a 10-year period: a retrospective report, J Periodontol 79(12): 2378-2382.

2. Ki Young N, Jong Bae K (2014) Treatment of dental implant-related maxillary sinusitis with functional endoscopic sinus surgery in combination with an intra-oral approach. Korean Assoc Oral Maxillofac Surg 40(2): 87-90.

3. Alper A, Nükhet Ç, Burcu B (2008) Acute Maxillary Sinusitis Associated with Internal Sinus Lifting: Report of a Case, Eur J Dent 2(1): 69-72.

4. Karl M (2016) Outcome of bonded vs all-ceramic and metal-ceramic fixed prostheses for single tooth replacement, Eur J Oral Implantol 9(Suppl1): 25-44.

5. Komine F, Blatz MB, Matsumura H (2010) Current status of zirconiabased fixed restorations. J Oral Sci 52(4): 531-539.

6. Agustín Panadero R, Román Rodríguez JL, Ferreiroa A, Solá-Ruíz MF, FonsFont A (2014) Zirconia in fixed prosthesis. A literature review, J Clin Exp Dent 6(1): e66-e73.

7. Schmitt J, Holst S, Wichmann M, Reich S, Gollner M, et al. (2009) Zirconia posterior fixed partial dentures: a prospective clinical 3-year follow-up, Int J Prosthodont 22(6): 597-603.

8. Koutayas SO, Vagkopoulou T, Pelekanos S, Koidis P, Strub JR (2009) Zirconia in dentistry: part 2. Evidence-based clinical breakthrough, Eur J Esthet 4(4): 348-380.

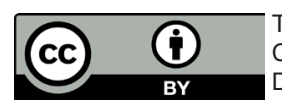

This work is licensed under Creative Commons Attribution 4.0 License DOI: 10.19080/ADOH.2018.09.555758
9. Larsson C (2011) Zirconium dioxide based dental restorations. Studies on clinical performance and fracture behavior. Swed Dent J Suppl (213): 9-84.

10. Goodacre CJ, Naylor WP (2016) Single implant and crown versus fixed partial denture: A cost-benefit, patient-centred analysis, Eur J Oral Implantol 9(Suppl 1): S59-S68.

11. Jung RE, Grohmann P, Sailer I, Steinhart YN, Fehér A, et al. (2016) Evaluation of a one-piece ceramic implant used for single-tooth replacement and three-unit fixed partial dentures: a prospective cohort clinical trial. Clin Oral Implants Res 27(7): 751-61.

12. Zarone F, Russo S, Sorrentino R (2011) From porcelain-fused-to-metal to zirconia: clinical and experimental considerations, Dent Mater 27(1): 83-96.

13. Sadowsky SJ (2006) An overview of treatment considerations for esthetic restorations: a review of the literature,J Prosthet Dent 96(6): 433-442.

14. Raut A, Rao PL, Ravindranath $\mathrm{T}$ (2011) Zirconium for esthetic rehabilitation: An overview, Indian journal of dental research 22(1): 140-143.

15. Vagkopoulou T, Koutayas SO, Koidis P, Strub JR (2009) Zirconia in dentistry part I: Discovering the nature of an upcoming bioceramic. Eur J Esthet Dent 4(2): 130-151.

16. Daou EE (2014) The Zirconia Ceramic: Strengths and Weaknesses. Open Dent J 8: 33-42.

17. Gautam C, Joyner J, Gautam A, Rao J, Vajtai R (2016) Zirconia based dental ceramics: structure, mechanical propreties, biocompatibility and applications. Dalton Trans 45(48): 19194-19215.

18. Špehar D, Jakovac M (2015) New Knowledge about Zirconium-Ceramic as a Structural Material in Fixed Prosthodontics. Acta Stomatol Croat 49(2): 137-144.

19. Schmitter M, Mussotter K, Rammelsberg P, Gabbert O, Ohlmann B (2012) Clinical performance of long-span zirconia frameworks for fixed dental prostheses: 5-year results. J Oral Rehabil 39(7): 552-557.

20. Beuer F, Sachs C, Groesser J, Gueth JF, Stimmelmayr M (2016) Toothimplant-supported posterior fixed dental prostheses with zirconia framework: 3-years clinical result. Clin Oral Invest 20(5): 1079-1086.

21. Miura S, Kasahara S, Kudo M, Okuyama Y, Izumida A, et al. (2014) Clinical Chipping of Zirconia All-Ceramic Restorations. Interface Oral Health Science pp. 317-323.

22. Matsuzaki F, Sekine H, Honma S, Takanashi T, Furuya K, et al. (2015) Translucency and flexural strength of monolithic translucent zirconia and porcelain-layered zirconia. Dent Mater J 34(6): 910-991.

\section{Your next submission with Juniper Publishers will reach you the below assets}

- Quality Editorial service

- Swift Peer Review

- Reprints availability

- E-prints Service

- Manuscript Podcast for convenient understanding

- Global attainment for your research

- Manuscript accessibility in different formats

( Pdf, E-pub, Full Text, Audio)

- Unceasing customer service

Track the below URL for one-step submission https://juniperpublishers.com/online-submission.php 